\title{
Stereotactic Body Radiation Therapy Versus Nonradiotherapeutic Ablative Procedures (Laser/Cryoablation and Electrocautery) for Early-Stage Non-Small Cell Lung Cancer
}

Michael J. Baine, MD, PhDa,*; Richard Sleightholm, BS ${ }^{b, c, *}$; Beth K. Neilsen, PhD'; David Oupický, PhD; Lynette M. Smith, PhDc; Vivek Verma, MDe; and Chi Lin, MD, PhDa

\section{ABSTRACT}

Background: Despite the fact that stereotactic body radiation therapy (SBRT) is the only recommended first-line therapy for inoperable early-stage non-small cell lung cancer (NSCLC), several thermal ablative procedures (TAPs; defined herein as laser/cryoablation and electrocautery) are available. Studies showing outcomes of these procedures and how they compare with SBRT are scarce. We sought to evaluate the comparative efficacy of SBRT versus TAPs using the National Cancer Database (NCDB). Methods: The NCDB was queried for patients with early-stage NSCLC who did not undergo surgical resection. Treatment-specific inclusion criteria were applied to select for patients receiving either TAPs or SBRT. Univariate logistic regression and Cox proportional hazards modeling were performed, and Kaplan-Meier curves were generated. Serial propensity matches were performed using a modified greedy $8 \rightarrow n$ matching 1:1 algorithm. Results: A total of 27,734 patients were analyzed; 26,725 underwent SBRT and 1,009 underwent TAPs. Patients who received SBRT were older and more likely to have clinical stage IB (vs IA) disease. Despite this, SBRT was associated with longer median overall survival (mOS; 37.7 vs 33.5 months; $P=.001$ ) and $1-, 2$-, and 5 -year OS rates compared with the TAPs cohort $(86.7 \%$ vs $83.1 \%, 67.5 \%$ vs $62.7 \%$, and $30.6 \%$ vs $26.9 \%$, respectively; $P=.001$ ). Upon propensity matching, improved OS with SBRT remained, with a mOS of 40.4 versus 33.4 months and $1-, 2-$, and 5 -year OS rates of $89.0 \%$ versus $82.9 \%, 69.7 \%$ versus $62.7 \%$, and $34.4 \%$ versus $26.4 \%$, respectively ( $P=.003$ ). Conclusions: Despite being associated with more higher-risk factors, SBRT was associated with higher OS compared with TAPs for treatment of nonoperative patients diagnosed with early-stage NSCLC. However, causation cannot be implied owing to the inherent limitations of large heterogeneous datasets such as the NCDB.

J Natl Compr Canc Netw 2019;17(5):450-458 doi: 10.6004/jnccn.2018.7269

\footnotetext{
aDepartment of Radiation Oncology, Fred \& Pamela Buffett Cancer Center, University of Nebraska Medical Center, Omaha, Nebraska; ${ }^{b}$ Department of Pharmaceutical Sciences, and 'Department of Biostatistics, College of Public Health, University of Nebraska Medical Center, Omaha, Nebraska; ${ }^{\mathrm{d}}$ Eppley
Institute, Fred and Pamela Buffett Cancer Center, University of Nebraska Health, University of Nebraska Medical Center, Omaha, Nebraska; ${ }^{\mathrm{d}}$ Eppley Medical Center, Omaha, Nebraska; and 'Department of Radiation Oncology, Allegheny General Hospital, Pittsburgh, Pennsylvania.
}

*These authors contributed equally.

\section{Background}

Patients diagnosed with early-stage non-small cell lung cancer (NSCLC) have multiple evidence-based treatment options. Although lobectomy remains the standard of care in medically operable patients, up to $85 \%$ to $90 \%$ are not surgical candidates at the time of diagnosis, owing mostly to comorbidities such as chronic obstructive pulmonary disease, heart disease, ongoing tobacco abuse, or patient preference. ${ }^{1}$ Classically, these patients were treated with conventionally fractionated radiation therapy (RT), which provided suboptimal local control rates. ${ }^{2,3}$ In recent years, stereotactic body RT (SBRT; also known as stereotactic ablative RT), has gained momentum for this purpose. ${ }^{4-6}$ To date, multiple prospective trials have reported local control rates of at least $90 \%$ at 1 year and $>80 \%$ at 3 years, with largely an absence of significant high-grade toxicities. ${ }^{7-10}$ Furthermore, a pooled analysis from 2 prospective clinical trials reported that SBRT may produce equivalent or even superior outcomes compared with surgical resection for operable patients. ${ }^{11}$ Although these findings are supportive of SBRT, it should be noted that neither study completed patient accrual, and the analysis was performed in an unplanned manner on the patients who did enroll. ${ }^{12}$ Thus, most current evidence for SBRT remains in the setting of inoperability, and its utility in patients who could otherwise undergo resection is under intense investigation (ie, the STABLEMATES and VALOR trials; ClinicalTrials.gov identifiers: NCT02468024 and NCT02984761, respectively).

SBRT is the current recommended first-line therapy for inoperable early-stage NSCLC, with thermal ablative procedures (TAPs) that do not involve ionizing radiation being available for select patients. TAPs include radiofrequency ablation (RFA), microwave ablation (MWA),

See JNCCN.org for supplemental online content. 
electrocautery, cryoablation, and electroporation. ${ }^{13,14}$ Due to the novelty and rapid acceptance of SBRT, outcomes data from these procedures are scarce. Early (and largely single-institutional) studies using TAPs reported local control rates of $42 \%$ to $69 \%$, along with relatively high rates of treatment-associated toxicities, particularly pneumothorax $(42 \%-63 \%)$ and chest tube placement (7\%-63\%). ${ }^{15-17}$ In a retrospective comparison of RFA versus wedge resection, Ambrogi et $\mathrm{al}^{18}$ observed suboptimal local control ( $77 \%$ vs $98 \%$ ), 2-year OS ( $72 \%$ vs $96 \%)$, and 3 -year OS (35\% vs $52 \%$ ) with RFA.

Two phase II trials attempted to assess the efficacy of TAPs in inoperable patients with early-stage NSCLC. In 2008, the prospective, intention-to-treat, multicenter RAPTURE trial involving 105 patients with 183 tumors treated with RFA reported a 2 -year OS of $48 \%$ and a $26 \%$ rate of postprocedure pneumothorax requiring chest tube placement. Additionally, although no long-term local control data were presented, $88 \%$ of patients had a complete response in the treated lesion at 1 year after treatment. Importantly though, only 33 of the included patients were diagnosed with NSCLC, with the remainder being treated for pulmonary metastases, thus limiting the interpretability of the presented efficacy of TAPs. ${ }^{19}$ More recently, ACOSOG Z4033 reported a 2-year local control rate of $60 \%$ and a 2-year OS of $70 \%$ in 54 patients with stage IA NSCLC treated with RFA. ${ }^{13}$ Consistent with past results, $22 \%$ of treated patients experienced grade $\geq 3$ toxicities.

Recognizing the dearth of comparative data with SBRT, Ochiai et $\mathrm{al}^{20}$ conducted a small retrospective analysis of 95 patients with stage I NSCLC undergoing either RFA $(n=48)$ or SBRT $(n=47)$. Their data indicated similar rates of 3 -year local failure $(10 \%$ vs $7 \% ; P=.746)$ and OS ( $86 \%$ vs $80 \% ; P=.738$ ), with nearly identical rates of grade $\geq 3$ toxicity in both treatment arms. Conversely, $\mathrm{Bi}$ et $\mathrm{al}^{21}$ provided a meta-analysis of trials published from 2001 through 2012 using either RFA $(n=13)$ or SBRT $(n=31)$ for the treatment of stage I NSCLC and found that RFA was associated with worse local control at $1(77 \%$ vs $97 \%$ ), 2 ( $48 \%$ vs $92 \%$ ), 3 ( $55 \%$ vs $88 \%$ ), and 5 years ( $42 \%$ vs $86 \%$ ); however, this did not translate into statistical OS differences. Importantly, SBRT was also noted to have significantly reduced rates of grade $\geq 3$ toxicities $(2 \%)$ compared with RFA (31\%).

Multidisciplinary discussion panels and patients often consider TAPs as an alternative to SBRT, with few large-volume assessments to guide clinical decisionmaking. Our study sought to evaluate the comparative efficacy of SBRT versus TAPs using the National Cancer Database (NCDB).

\section{Methods}

The NCDB is a joint project of the Commission on Cancer (CoC) of the American College of Surgeons and the
American Cancer Society that consists of information regarding tumor characteristics, patient demographics, and patient survival for approximately $70 \%$ of the US population..$^{22-24}$ The NCDB contains information not included in the SEER database, including details regarding use of systemic therapy. The American College of Surgeons and $\mathrm{CoC}$ have not verified and are not responsible for the analytic or statistical methodology used or the conclusions drawn from these data. Because all patient information in the NCDB database is deidentified, this study was exempt from Institutional Review Board evaluation.

The NCDB NSCLC database (2004-2014) was used for this study. Patients with early-stage NSCLC were identified using the following inclusion criteria: (1) clinical stage I disease, (2) pathologically confirmed disease, and (3) no surgical resection. The following exclusion criteria were then applied: clinical stage other than I (ie, I, IA, or IB), pathologic or clinical diagnosis of nodal disease (including coding for regional nodal positivity), missing information regarding vital and outcome status, intervention with palliative intent, and prior administration of chemotherapy. Finally, treatmentspecific criteria were applied so that patients received either TAPs, defined as laser ablation/cryotherapy (surgical code 12) or electrocautery (surgical code 13), or SBRT (using regional treatment modality-specific codes), with defined doses for stereotactic treatment of 48, 50, 54, or $60 \mathrm{~Gy}$ (see supplemental eTable 1, available with this article at JNCCN.org).

In accordance with the variables in NCDB files, information collected on each patient broadly included demographic, clinical, and treatment data, as well as survival outcomes. All statistical analyses were performed using SAS 9.4 (SAS Institute Inc.). All tests were conducted in a 2 -sided manner, with $P<.05$ considered statistically significant. Univariate logistic regression was performed to determine variables associated with receiving SBRT. Any variable with a $P$ value $\leq .10$ was considered in a subsequent logistic regression multivariable model using a backward selection approach, with an $\alpha=0.1$ for variable retention in the final model. Similarly, a Cox proportional hazard (Cox PH) model was generated to identify variables associated with survival among the entire cohort of patients, and all variables of interest were then included in a multivariable Cox $\mathrm{PH}$ model. Patients denoted as alive were treated as censored in all survival analyses. Kaplan-Meier curves were constructed to illustrate differences in survival between treatment cohorts, and OS and median OS (mOS) were assessed using log-rank testing.

Propensity matching was used to account for any bias that may have led patients to receive one treatment modality over the other (TAPs vs SBRT). Using variables 
outlined in the logistic regression procedure described earlier and any other clinically relevant variable, a modified greedy $8 \rightarrow \mathrm{n}$ (ie, greedy $8 \rightarrow 7 \ldots$ greedy $8 \rightarrow 1$ ) matching 1:1 algorithm was implemented. For propensity matching, Charlson-Deyo comorbidity scores were counted individually instead of combined into groups to ensure optimal matching. Various propensitymatched models were constructed to balance matching completeness with goodness of fit. In efforts to perform the highest quality of propensity matching, unmatched patients and any matches that demonstrated a $>2 \%$ difference in propensity scores were eliminated from further analysis. Patient demographics were reassessed for each model chosen using appropriate paired tests (ie, paired $t$ testing, McNemar testing, etc.) and compared with the original patient population. Additionally, Kaplan-Meier curves were used to describe any difference in OS between treatment cohorts.

\section{Results}

A total of 27,734 patients met study criteria, including 26,725 patients (96\%) who underwent SBRT and 1,009 (4\%) who underwent TAPs (Figure 1). Patients had a relatively even distribution in terms of sex, but were predominately white. On multivariable analysis, characteristics that remained associated with receipt of SBRT were geographic region of the treating facility, receiving treatment at an academic institute versus a community cancer center, older age, a more recent diagnosis, having clinical stage IB disease, and histologic subtype (Table 1 and supplemental eTable 2).

Median follow-up was 26.7 months, with $43.9 \%$ of patients recorded as alive. Rates of 30- and 90-day mortality for SBRT versus TAPs were $0.01 \%$ versus $0.7 \%$ and $0.5 \%$ versus $3.8 \%$, respectively. On Cox PH analysis, receipt of SBRT, younger age, female sex, black race, lower Charlson-Deyo comorbidity scores, histology other than squamous, lower tumor grade, and clinical stage IA versus IB disease were associated with reduced hazards for death (Table 2 and supplemental eTable 3). On Kaplan-Meier analysis, OS rates were significantly longer in patients treated with SBRT compared with those treated with TAPs (1-year OS: $86.7 \%$ [95\% CI, $86.3 \%-87.1 \%$ ] vs $83.1 \%$ [80.6\%-85.3\%]; 2-year OS: $67.5 \%$ [66.9\%-68.1\%] vs $62.7 \%$ [59.6\%-65.7\%]; and 5-year OS: $30.6 \%$ [29.9\%-31.4\%] vs $26.9 \%$ [23.7\%-30.2\%]; $P=.001$; Figure 2 and supplemental eFigure 1). This corresponded to an mOS of 37.7 months (95\% CI, 37.2-38.3) and 33.5 months (95\% CI, 30.9-36.5) for each group, respectively $(P=.001)$.

To minimize bias within the data, 1:1 propensity matching using a greedy $8 \rightarrow 1$ algorithm was performed. After excluding any matches with $>2 \%$ difference in propensity scores, 987 pairs $(97.8 \%$ of all patients treated

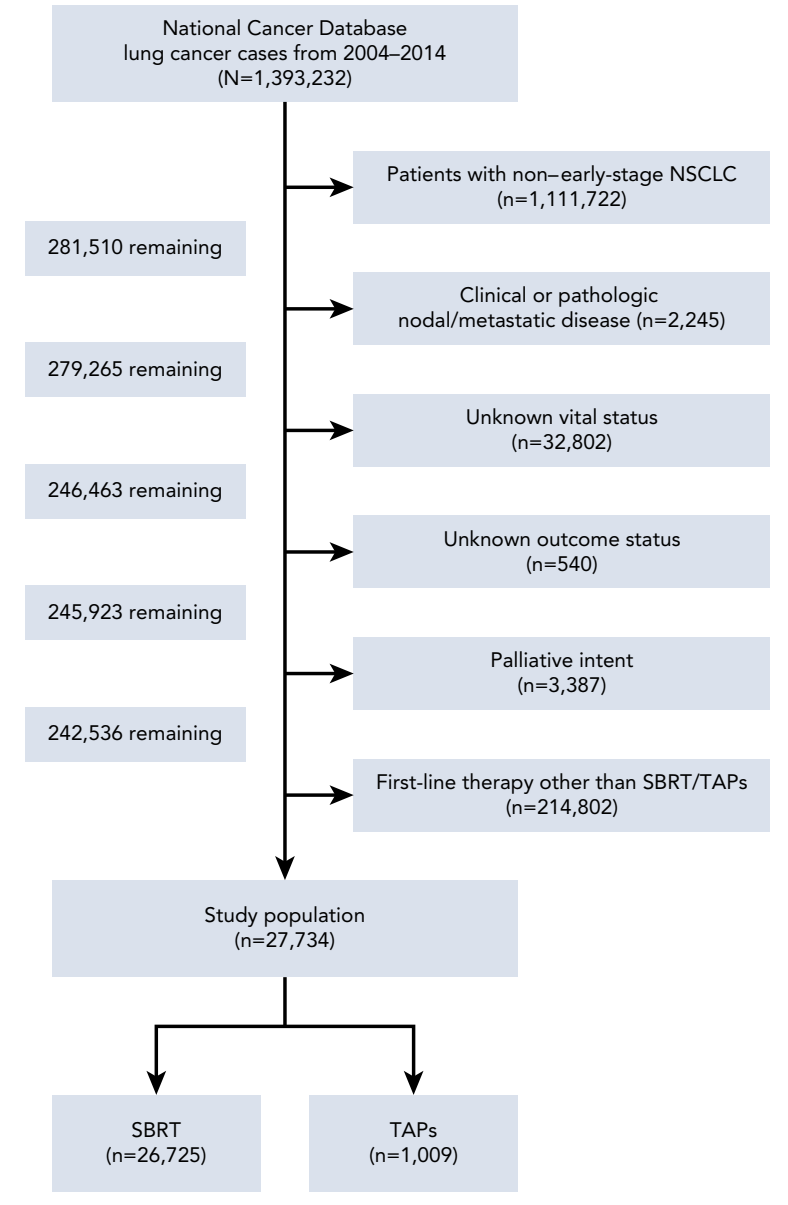

Figure 1. Patient selection flowchart.

Abbreviations: NSCLC, non-small cell lung cancer; SBRT, stereotactic body radiation therapy; TAPs, thermal ablative procedures.

with TAPs) were included for subsequent analysis. Models based solely on 8-digit nearest-neighbor matches and sequential greedy matching $8 \rightarrow 7$ to $8 \rightarrow 1$ were also generated. Matching completeness and goodness of matches were analyzed for each of these models (supplemental eTable 4). Greedy $8 \rightarrow 6$ matching resulted in only $22 \%$ of patient inclusion, whereas greedy $8 \rightarrow 5$ incorporated $>60 \%$ of possible matched pairs. Greedy $8 \rightarrow 4$ further increased the patient inclusion to nearly $85 \%$, but had a near logarithmic increase in average difference in propensity scores. Despite the difference in propensity scores, greedy $8 \rightarrow 5$, greedy $8 \rightarrow 4$, and greedy $8 \rightarrow 1$ displayed median ages of 75.0 years for patients who underwent SBRT or TAPs, with demographics varying only slightly between models. The greedy $8 \rightarrow 4$ model was selected as the comparison model that balanced patient inclusion with best matching pairs (Table 3 and supplemental eTable 5). After greedy $8 \rightarrow 4$ matching, univariable logistic regression revealed similar clinical characteristics between cohorts, although tumor size 


\section{Table 1. Patient Demographics}

\begin{tabular}{|c|c|c|c|c|c|c|}
\hline \multirow[b]{2}{*}{ Parameter } & \multirow{2}{*}{$\begin{array}{c}\text { SBRT } \\
(\mathrm{N}=26,725)\end{array}$} & \multirow{2}{*}{$\begin{array}{c}\text { TAPs } \\
(\mathrm{N}=1,009)\end{array}$} & \multicolumn{2}{|l|}{ Univariable ${ }^{a}$} & \multicolumn{2}{|l|}{ Multivariable $^{a}$} \\
\hline & & & OR $(95 \% \mathrm{Cl})$ & $P$ Value & OR $(95 \% \mathrm{Cl})$ & P Value \\
\hline Median age (IQR), y & $75.0(69-81)$ & $74.0(67-81)$ & $1.015(1.008-1.022)$ & $<.001$ & $1.012(1.005-1.020)$ & .001 \\
\hline \multicolumn{7}{|l|}{ Sex } \\
\hline Male & $12,460(46.6)$ & $485(48.1)$ & Ref & & Ref & \\
\hline Female & $14,265(53.4)$ & $524(51.9)$ & $1.060(0.934-1.202)$ & .367 & $0.891(0.782-1.014)$ & .080 \\
\hline Academic institute & $11,751(44.0)$ & $496(49.2)$ & Ref & & Ref & \\
\hline Community cancer program & $822(3.1)$ & $56(5.6)$ & $0.619(0.466-0.824)$ & $<.001$ & $0.506(0.376-0.682)$ & .015 \\
\hline Comprehensive community cancer program & $10,647(39.8)$ & $327(32.4)$ & $1.374(1.192-1.584)$ & $<.001$ & $1.115(0.959-1.297)$ & .643 \\
\hline Integrated network cancer program & $3,501(13.1)$ & $121(12.0)$ & $1.221(0.998-1.495)$ & .862 & $1.113(0.895-1.383)$ & .783 \\
\hline Unknown & $4(0.0)$ & $9(0.9)$ & & & & \\
\hline South Atlantic & $5,934(22.2)$ & $193(19.1)$ & $3.379(2.718-4.200)$ & $<.001$ & $3.452(2.746-4.339)$ & $<.001$ \\
\hline East North Central & $5,351(20.0)$ & $177(17.5)$ & $3.322(2.661-4.147)$ & $<.001$ & $3.394(2.690-4.283)$ & $<.001$ \\
\hline East South Central & $1,670(6.2)$ & $63(6.2)$ & $2.913(2.158-3.933)$ & $<.001$ & $2.543(1.865-3.468)$ & $<.001$ \\
\hline West North Central & $3,355(12.6)$ & $45(4.5)$ & $8.193(5.851-11.472)$ & $<.001$ & $9.193(6.523-12.954)$ & $<.001$ \\
\hline West South Central & $1,512(5.7)$ & $72(7.1)$ & $2.308(1.731-3.077)$ & $<.001$ & $2.566(1.905-3.457)$ & $<.001$ \\
\hline Mountain & $996(3.7)$ & $27(2.7)$ & $4.054(2.674-6.144)$ & $<.001$ & $3.714(2.427-5.683)$ & $<.001$ \\
\hline Pacific & $2,346(8.8)$ & $53(5.3)$ & $4.866(3.542-6.686)$ & $<.001$ & $4.525(3.257-6.289)$ & $<.001$ \\
\hline Unknown & $4(0.0)$ & $9(0.9)$ & & & & \\
\hline \multicolumn{7}{|l|}{ Histology } \\
\hline $\mathrm{IA}$ & $19,856(74.3)$ & $821(81.4)$ & Ref & & Ref & \\
\hline IB & $5,659(21.2)$ & $135(13.4)$ & $1.733(1.441-2.084)$ & $<.001$ & $1.860(1.538-2.249)$ & $<.001$ \\
\hline "I" NOS & $1,210(4.5)$ & $53(5.2)$ & $0.944(0.711-1.254)$ & .231 & $0.967(0.719-1.299)$ & .251 \\
\hline \multicolumn{7}{|l|}{ Tumor grade } \\
\hline 1 & $2,156(8.1)$ & $91(9.0)$ & Ref & & Ref & \\
\hline 2 & $4,446(16.6)$ & $183(18.1)$ & $1.025(0.793-1.325)$ & .603 & $0.872(0.663-1.145)$ & .055 \\
\hline 3 & $5,052(18.9)$ & $171(16.9)$ & $1.247(0.962-1.616)$ & .771 & $1.164(0.883-1.536)$ & .515 \\
\hline 4 & $95(0.4)$ & $6(0.7)$ & $0.668(0.285-1.566)$ & .253 & $1.311(0.536-3.210)$ & .603 \\
\hline Unknown & $14,976(56.0)$ & $558(55.3)$ & & & & \\
\hline
\end{tabular}

Statistically significant $P$ values are bold.

Abbreviations: IQR, interquartile range; NOS, not otherwise specified; OR, odds ratio; SBRT, stereotactic body radiation therapy; TAPs, thermal ablative procedures. aEnd point: receipt of SBRT.

could still not be adequately matched and remained statistically lower in the TAP group.

Cox PH analysis of the $8 \rightarrow 4$ matched data showed that the following were associated with a lower hazard for death: receipt of SBRT compared with TAPs, younger age, female sex, lower Charlson-Deyo comorbidity score, facility location, histology other than squamous cell, lower tumor grade, smaller tumor size, and less advanced 


\begin{tabular}{|c|c|c|c|c|c|c|}
\hline Parameter & HR & $95 \% \mathrm{Cl}$ & $P$ Value & HR & $95 \% \mathrm{Cl}$ & $P$ Value \\
\hline Treatment (TAPs vs SBRT) & 1.136 & $1.052-1.226$ & .001 & 1.330 & $1.171-1.510$ & $<.001$ \\
\hline Age (continuous) & 1.015 & $1.013-1.017$ & $<.001$ & 1.013 & $1.010-1.017$ & $<.001$ \\
\hline Sex (female vs male) & 0.750 & $0.727-0.774$ & $<.001$ & 0.778 & $0.739-0.818$ & $<.001$ \\
\hline Black vs white & 0.848 & $0.798-0.900$ & $<.001$ & 0.868 & $0.786-0.959$ & .006 \\
\hline Indian vs white & 1.164 & $0.866-1.565$ & .314 & 1.146 & $0.728-1.802$ & .556 \\
\hline Pacific Islander vs white & 0.669 & $0.470-0.999$ & .019 & 0.836 & $0.617-1.131$ & .245 \\
\hline Charlson-Deyo comorbidity score ( $\geq 3$ vs $0-2$ ) & 1.594 & $1.487-1.708$ & $<.001$ & 1.539 & $1.383-1.712$ & $<.001$ \\
\hline East North Central vs New England & 1.033 & $0.960-1.112$ & .383 & 1.019 & $0.892-1.163$ & .783 \\
\hline East South Central vs New England & 1.090 & $0.996-1.193$ & .062 & 0.998 & $0.851-1.170$ & .977 \\
\hline West North Central vs New England & 1.016 & $0.939-1.098$ & .693 & 1.005 & $0.879-1.150$ & .939 \\
\hline West South Central vs New England & 0.863 & $0.786-0.947$ & .002 & 0.883 & $0.757-1.030$ & .114 \\
\hline Mountain vs New England & 0.971 & $0.875-1.078$ & .584 & 0.944 & $0.795-1.120$ & .507 \\
\hline Pacific vs New England & 0.902 & $0.828-0.983$ & .018 & 0.871 & $0.750-1.012$ & .071 \\
\hline \multicolumn{7}{|l|}{ Histology } \\
\hline Adenocarcinoma vs squamous & 0.726 & $0.700-0.753$ & $<.001$ & 0.828 & $0.782-0.877$ & $<.001$ \\
\hline Non-small vs squamous & 0.859 & $0.821-0.899$ & $<.001$ & 0.903 & $0.823-0.991$ & .031 \\
\hline
\end{tabular}

Statistically significant $P$ values are bold.

Abbreviations: HR, hazard ratio; SBRT, stereotactic body radiation therapy; TAPs, thermal ablative procedures.

clinical stage (IA vs IB; supplemental eTable 6). On multivariable analysis, only receipt of SBRT versus TAPs, younger age, lower Charlson-Deyo comorbidity score, and less advanced clinical stage remained significantly associated with a decreased hazard ratio (supplemental eTable 6). Of note, tumor size was excluded from the multivariable analysis due to its correlation with clinical stage. Subsequent survival analyses revealed mOS of 40.4 versus 33.4 months, and 1-, 2-, and 5-year OS of $89.0 \%$ versus $82.9 \%, 69.7 \%$ versus $62.7 \%$, and $34.4 \%$ versus $26.4 \%$ between the SBRT and TAPs cohorts, respectively $(P=.0033$; Figure 3 and stratification for $\mathrm{T}$ stage in supplemental eFigure 2). Both the greedy $8 \rightarrow 1$ and $8 \rightarrow 5$ models demonstrated similar results (supplemental eFigure 3 and eTable 7).

To determine whether the reduced OS associated with TAPs was due to higher rates of acute iatrogenic toxicity associated with these procedures compared with SBRT, Kaplan-Meier analyses were performed, excluding all patients who died within 6 months of their respective procedures. Unmatched and propensity-matched data generated using greedy $8 \rightarrow 1,8 \rightarrow 4$, and $8 \rightarrow 5$ models showed that patients who underwent SBRT had a persistent OS advantage compared with their TAPs counterparts (data not shown).

\section{Discussion}

Because a significant proportion of patients with earlystage NSCLC are not candidates for surgical resection, noninvasive methods such as SBRT or TAPs are important alternative treatment options. Primarily due to treatment novelty, no large-scale clinical trials have attempted to compare currently available noninvasive treatments for NSCLC in terms of patient outcomes. 


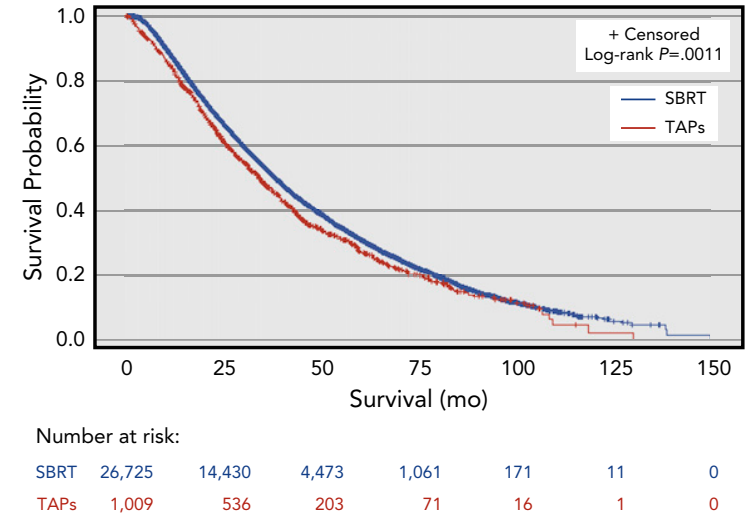

Figure 2. Kaplan-Meier curve of overall survival for patients undergoing SBRT versus TAPs-based procedures.

Abbreviations: SBRT, stereotactic body radiation therapy; TAPs, thermal ablative procedures.

Consequently, patient and provider decision-making between available treatment options has been limited to comparative analyses across various single-modality prospective studies or small-scale retrospective analyses. Our study addresses this knowledge gap and demonstrates that SBRT may be associated (without implying causation) with improved OS compared with TAPs.

Through the use of data collected in the NCDB, we were able to analyze outcomes for 27,734 patients with early-stage NSCLC treated with either SBRT or TAPs. In this cohort, patients who received TAPs tended to be younger and have lower-stage disease with similar Charlson-Deyo comorbidity scores, indicating a potential difference in patient populations being treated with TAPs compared with SBRT. As such, treatment with SBRT was associated with a slightly longer mOS of 4.2 months. On propensity matching, cohorts were nearly identical, and the survival difference between treatment groups was even more pronounced (7.0 months). These findings suggest an inherent selection bias against SBRT (ie, favoring TAPs), despite which SBRT remained associated with higher mOS.

There are several potential reasons for the improved OS with SBRT. Increased local failure may increase the risk of cancer-specific death through local progression or development of associated distant metastatic disease. Another potential explanation is that SBRT has been associated with incidental mediastinal dose, which may have meaningful implications with regard to treatment of occult regional metastatic disease, a concept which would not be present in the setting of TAPs. ${ }^{25}$

One big confounder that must also be considered is the difference in patient populations. For example, was the reason for not being surgical candidates similar between cohorts? Additionally, TAPs may be considered as alternatives for patients who may not be eligible for SBRT, and these patients may have more comorbidities and a higher risk of mortality, leading to a negative skewing of survival data. Although this is a seemingly plausible scenario, very few inoperable patients who cannot undergo SBRT would actually be candidates for TAPs. After matching for as many variables present in NCDB, including Charlson-Deyo comorbidity scores, differences in survival between TAPs and SBRT were even more pronounced. Furthermore, the intent of each therapy may be different. For example, providers offering SBRT may be doing so with a curative intent, whereas providers of TAPs may be offering the procedure for palliation. If this was true, one would suspect that the cancer was disseminated, that the tumor was larger, or some other reason why TAPs may be more appropriate than SBRT. Although we were unable to establish a reason why each modality was offered to each patient, cancer and tumor characteristics (ie, stage, size) were similar between cohorts. Thus, there may be a reason why the TAPs cohort received TAPs over SBRT; however, due to limited data provided in the NCDB, we cannot ascertain why, only that patients between cohorts are similar by all metrics included in the NCDB.

Other studies have compared TAPs with SBRT, ${ }^{26}$ but had major shortcomings that severely hampered the conclusions, including lack of describing prematching survival, matching, and goodness-of-fit methodologies, and a lack of multivariate analysis. To this extent, the multiple propensity-matching algorithms we used should be considered a more robust way to control unforeseen biases. However, despite the flawed methodologies in other such studies, we posit that TAPs can be excellent alternatives to SBRT in the re-irradiation setting for post-SBRT isolated local recurrences. ${ }^{27}$

Overall, limitations in this work are varied. Foremost, despite use of multivariate analyses and propensity matching, the retrospective design of this study never entirely eliminates the presence of potential bias that cannot be accounted for. As such, we cannot ensure that patient populations between the cohorts are truly identical, which is a limitation of the NCDB. Additionally, because NCDB data depend on precise diagnosis and treatment coding, possible mistakes made during data input may result in patients being erroneously included within the analyzed groups. Due to the coding provided, the NCDB also prevents thorough analysis into the individual TAPs and thus does not allow each technique to be directly compared with SBRT. Moreover, due to its retrospective and large-scale design, the NCDB disallows assessment of whether SBRT or TAPs were provided to the analyzed patients in a technically sound manner. Furthermore, the NCDB only allows for analysis of OS, 
Table 3. Patient Demographics for Propensity-Matched Patients Using the Greedy $8 \rightarrow 4$ Model

\begin{tabular}{|c|c|c|c|}
\hline Parameter & $\begin{array}{c}\text { SBRT (N=853) } \\
n(\%)\end{array}$ & $\begin{array}{c}\text { TAPs }(\mathbf{N}=853) \\
n(\%)\end{array}$ & $\frac{\text { Univariable }^{\mathrm{a}}}{P \text { Value }}$ \\
\hline Median age (IQR), y & $75.0(69-80)$ & $74.0(68-81)$ & \\
\hline \multicolumn{4}{|l|}{ Sex } \\
\hline Male & $405(47.5)$ & $411(48.2)$ & \\
\hline Female & $448(52.5)$ & $442(51.8)$ & \\
\hline \multicolumn{4}{|l|}{ Facility type } \\
\hline Academic institute & $410(48.1)$ & $398(46.7)$ & \\
\hline Community cancer program & $45(5.3)$ & $43(5.0)$ & \\
\hline Comprehensive community cancer program & $287(33.6)$ & $299(35.1)$ & \\
\hline Integrated network cancer program & $111(13.0)$ & $113(13.2)$ & \\
\hline Unknown & - & - & \\
\hline \multicolumn{4}{|l|}{ Facility location } \\
\hline New England & $89(10.4)$ & $80(9.4)$ & \\
\hline Middle Atlantic & $174(20.4)$ & $180(21.1)$ & \\
\hline South Atlantic & $161(18.9)$ & $179(21.0)$ & \\
\hline East North Central & $183(21.5)$ & $172(20.2)$ & \\
\hline East South Central & $45(5.3)$ & $56(6.6)$ & \\
\hline West North Central & $52(6.1)$ & $43(5.0)$ & \\
\hline West South Central & $69(8.1)$ & $66(7.7)$ & \\
\hline Mountain & $33(3.9)$ & $27(3.2)$ & \\
\hline Pacific & $47(5.5)$ & $50(5.9)$ & \\
\hline Unknown & - & - & \\
\hline \multicolumn{4}{|l|}{ Histology } \\
\hline Squamous & $264(30.9)$ & $293(34.3)$ & \\
\hline Adenocarcinoma & $405(47.5)$ & $362(42.5)$ & \\
\hline Non-small cell NOS & $113(13.2)$ & $122(14.3)$ & \\
\hline Other & $71(8.4)$ & $76(8.9)$ & \\
\hline Mean year of diagnosis (IQR) & 2012 (2010-2013) & 2010 (2008-2012) & \\
\hline Median tumor size (IQR), mm & $21(15-29)$ & $18(14-25)$ & $<.001$ \\
\hline \multicolumn{4}{|l|}{ Clinical stage } \\
\hline IA & $680(79.7)$ & $682(80.0)$ & \\
\hline IB & $122(14.3)$ & $126(14.8)$ & \\
\hline "I" NOS & $51(6.0)$ & $45(5.3)$ & \\
\hline \multicolumn{4}{|l|}{ Tumor grade } \\
\hline 1 & $81(9.5)$ & $74(8.7)$ & \\
\hline 2 & $148(17.4)$ & $162(19.0)$ & \\
\hline 3 & $171(20.0)$ & $159(18.6)$ & \\
\hline 4 & $2(0.2)$ & $5(0.6)$ & \\
\hline Unknown & $451(52.9)$ & $453(53.1)$ & \\
\hline
\end{tabular}

Statistically significant $P$ values are bold.

Abbreviations: IQR, interquartile range; NOS, not otherwise specified; OR, odds ratio; SBRT, stereotactic body radiation therapy; TAPs, thermal ablative procedures. aEnd point: receipt of SBRT.

without any indication of local or regional progressionfree survival, development of distant metastatic disease, toxicities, or cause of death. Additionally, the potential to have missed patients based on NCDB coding for dose should be mentioned, because SBRT dosing is largely delivered to a particular volume or isodose line, which 


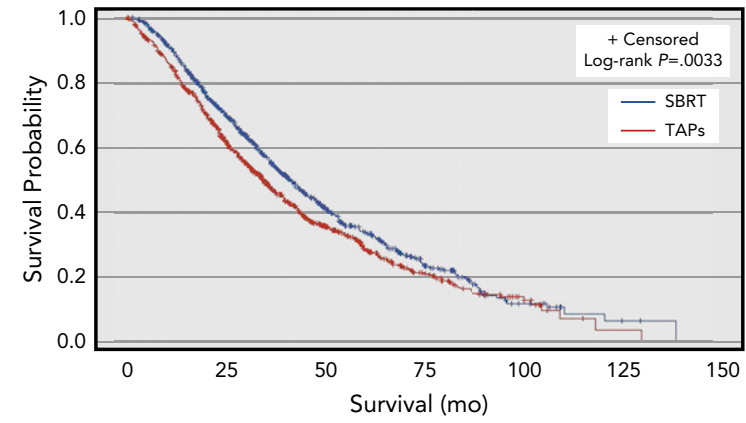

Number at risk:

$\begin{array}{llllllll}\text { SBRT } & 853 & 510 & 207 & 64 & 13 & 2 & 0 \\ \text { TAPs } & 853 & 449 & 165 & 53 & 11 & 1 & 0\end{array}$

Figure 3. Kaplan-Meier curve of overall survival for propensitymatched patients using greedy $8 \rightarrow 4$ matching.

Abbreviations: SBRT, stereotactic body radiation therapy; TAPs, thermal ablative procedures.

could alter the delivered dose to another isodose line or volume and thus would have been incompletely captured by this study. Lastly, we compared all available patients treated with TAPs as coded in the NCDB. However, cryoablation and laser ablation are coded using the same identifier, MWA and RFA are not uniquely coded in the lung NCDB, and there is a category termed "local tumor destruction, not otherwise specified" (supplemental eFigure 4). Therefore, it is impossible to determine outcomes for each of the TAPs individually, which may vary greatly. This is another large limitation of NCDB.

Despite these limitations, this study is an important step in understanding the nonsurgical management of early-stage NSCLC and provides impetus for multiple further studies. Most importantly, these results should be validated in a prospective manner. Further investigation is required to elucidate the cause of shorter OS with TAPs, in order to better delineate whether it is due to iatrogenic mortality, cancer-related death, or other causes. Additionally, patient outcomes should be separately compared across the various TAPs, including RFA, MWA, and electroporation, to determine whether one technique provides relatively better disease control or survival and thus may alone be equivalent to SBRT.

\section{Conclusions}

Results of our analysis suggest that, compared with TAPs, SBRT may be associated with longer OS in the treatment of nonoperative patients diagnosed with early-stage NSCLC. However, causation cannot be implied owing to the inherent limitations of large heterogeneous datasets such as the NCDB.

\section{Submitted May 24, 2018; accepted for publication January 4, 2019.}

Disclosures: The authors have disclosed that they have not received any financial considerations from any person or organization to support the preparation, analysis, results, or discussion of this article.

Funding: This work was supported by the $\mathrm{NCl}$ within $\mathrm{NIH}$ (F31CA224942 to R.S.). The $\mathrm{NCI}$ had no role in the design of the study; the collection, analysis, or interpretation of data; the writing of the manuscript; or the decision to submit the manuscript for publication.

Correspondence: Michael J. Baine, MD, PhD, Department of Radiation Oncology, Fred \& Pamela Buffett Cancer Center, University of Nebraska Medical Center, 987521 Nebraska Medical Center, Omaha, NE 68198-7521. Email: mbaine@unmc.edu

\section{References}

1. Ettinger DS, Wood DE, Aisner DL, et al. NCCN Clinical Practice Guidelines in Oncology: Non-Small Cell Lung Cancer. Version 3.2018. Accessed March 19, 2018. To view the most recent version of these guidelines, visit NCCN.org.

2. Ball D, Mai GT, Vinod S, et al. Stereotactic ablative radiotherapy versus standard radiotherapy in stage 1 non-small-cell lung cancer (TROG 09.02 CHISEL): a phase 3, open-label, randomised controlled trial. Lancet Oncol 2019;20:494-503.

3. Haque W, Verma V, Polamraju P, et al. Stereotactic body radiation therapy versus conventionally fractionated radiation therapy for early stage nonsmall cell lung cancer. Radiother Oncol 2018;129:264-269.

4. Videtic GM, Donington J, Guiliana M, et al. Stereotactic body radiation therapy for early-stage non-small cell lung cancer: executive summary of an ASTRO evidence-based guideline. Pract Radiat Oncol 2017;7: 295-301.

5. Verma V, Shostrom VK, Kumar SS, et al. Multi-institutional experience of stereotactic body radiotherapy for large ( $\geq 5$ centimeters) non-small cell lung tumors. Cancer 2017;123:688-696.

6. Verma V. Lung cancer: implementing lung-cancer screening-oncological 'grey areas'. Nat Rev Clin Oncol 2015;12:256-257.

7. Timmerman R, Paulus R, Galvin J, et al. Stereotactic body radiation therapy for inoperable early stage lung cancer. JAMA 2010;303: 1070-1076.

8. Sun B, Brooks ED, Komaki R, et al. 7-year follow-up outcomes after stereotactic ablation radiotherapy for stage I NSCLC: results of a phase II clinical trial. Cancer 2017:123:3031-3039.
9. Timmerman RD, Hu C, Michalski J, et al. Long-term results of RTOG 0236 a phase II trial of stereotactic body radiation therapy (SBRT) in the treatment of patients with medically inoperable stage I non-small cell lung cancer. Int J Radiat Oncol Biol Phys 2014;90:S30.

10. Videtic GM, Hu C, Singh AK, et al. A randomized phase 2 study comparing 2 stereotactic body radiation therapy schedules for medically inoperable patients with stage I peripheral non-small cell lung cancer: NRG Oncology RTOG 0915 (NCCTG N0927). Int J Radiat Oncol Biol Phys 2015;93:757-764.

11. Chang JY, Senan S, Paul MA, et al. Stereotactic ablative radiotherapy versus lobectomy for operable stage I non-small-cell lung cancer: a pooled analysis of two randomised trials. Lancet Oncol 2015;16:630-637.

12. Verma V. Stereotactic radiotherapy versus surgery for early-stage operable lung cancer: more questions than answers. J Natl Compr Canc Netw 2015 13:1293-1295.

13. Dupuy DE, Fernando HC, Hillman S, et al. Radiofrequency ablation of stage IA non-small cell lung cancer in medically inoperable patients: results from the American College of Surgeons Oncology Group Z4033 (Alliance) trial. Cancer 2015;121:3491-3498

14. De Baere T, Farouil G, Deschamps F. Lung cancer ablation: what is the evidence? Semin Intervent Radiol 2013;30:151-156.

15. Hiraki T, Gobara H, Iguchi T, et al. Radiofrequency ablation for early-stage nonsmall cell lung cancer. BioMed Res Int 2014;2014:152087.

16. Pennathur A, Luketich JD, Abbas G, et al. Radiofrequency ablation for the treatment of stage I non-small cell lung cancer in high-risk patients. J Thorac Cardiovasc Surg 2007;134:857-864 
17. Ambrogi MC, Fanucchi $\mathrm{O}$, Cioni $\mathrm{R}$, et al. Long-term results of radiofrequency ablation treatment of stage I non-small cell lung cancer: a prospective intention-to-treat study. J Thorac Oncol 2011;6:2044-2051.

18. Ambrogi MC, Fanucchi $O$, Dini $P$, et al. Wedge resection and radiofrequency ablation for stage I nonsmall cell lung cancer. Eur Respir J 2015; 45:1089-1097.

19. Lencioni $R$, Crocetti $L$, Cioni $R$, et al. Response to radiofrequency ablation of pulmonary tumours: a prospective, intention-to-treat, multicentre clinical trial (the RAPTURE study). Lancet Oncol 2008;9:621-628.

20. Ochiai S, Yamakado K, Kodama H, et al. Comparison of therapeutic results from radiofrequency ablation and stereotactic body radiotherapy in solitary lung tumors measuring $5 \mathrm{~cm}$ or smaller. Int J Clin Oncol 2015;20:499-507.

21. Bi N, Shedden $K$, Zheng $X$, et al. Comparison of the effectiveness of radiofrequency ablation with stereotactic body radiation therapy in inoperable stage I non-small cell lung cancer: a systemic review and pooled analysis. Int J Radiat Oncol Biol Phys 2016;95:1378-1390.

22. Bilimoria KY, Stewart AK, Winchester DP, et al. The National Cancer Data Base: a powerful initiative to improve cancer care in the United States. Ann Surg Oncol 2008;15:683-690.
23. Verma V, Allen PK, Simone CB II, et al. Addition of definitive radiotherapy to chemotherapy in patients with newly diagnosed metastatic nasopharyngeal cancer. J Natl Compr Canc Netw 2017; 15:1383-1391.

24. Verma V, Moreno AC, Haque W, et al. Sequential versus concurrent chemoradiation therapy by surgical margin status in resected non-small cell lung cancer. J Natl Compr Canc Netw 2018;16:508-516.

25. Kwong $\mathrm{S}$, Djemil $\mathrm{T}$, Vaghefi $\mathrm{H}$, et al. Incidental mediastinal nodal radiation during stereotactic radiation for lung tumors: implications for high-dose treatment of locally advanced disease. Int J Radiat Oncol Biol Phys 2012;84:S605-606.

26. Uhlig J, Ludwig JM, Goldberg SB, et al. Survival rates after thermal ablation versus stereotactic radiation therapy for stage 1 non-small cell lung cancer: a National Cancer Database study. Radiology 2018; 289:862-870.

27. Brooks ED, Sun B, Feng L, et al. Association of long-term outcomes and survival with multidisciplinary salvage treatment for local and regional recurrence after stereotactic ablative radiotherapy for early-stage lung cancer. JAMA Netw Open 2018;1:e181390. 
Supplemental online content for:

\section{Stereotactic Body Radiation Therapy Versus Nonradiotherapeutic Ablative Procedures (Laser/Cryoablation and Electrocautery) for Early-Stage Non-Small Cell Lung Cancer}

Michael J. Baine, MD, PhD; Richard Sleightholm, BS; Beth K. Neilsen, PhD; David Oupický, PhD; Lynette M. Smith, PhD; Vivek Verma, MD; and Chi Lin, MD, PhD

J Natl Compr Canc Netw 2019;17(5):450-458

eFigure 1: Kaplan-Meier Curve of Different Stereotactic Body Radiation Doses Comprising SBRT Cohort, and Different Thermal Ablation Procedures Comprising the TAPs Cohort

eFigure 2: Kaplan-Meier Curve for T1 and T2 Disease Between SBRT and TAPs Cohorts

eFigure 3: Kaplan-Meier Curve of Overall Survival for Propensity-Matched Patients Using Greedy $8 \rightarrow 1$ and $8 \rightarrow 5$ Matching

eFigure 4: Kaplan-Meier Curve of Different Thermal Ablation Procedures Available in the NCDB

eTable 1: Dose and Fractionation Patterns of the SBRT Cohort

eTable 2: Complete List of Patient Demographics

eTable 3: Complete Cox Proportional Analysis of Hazards for Death

eTable 4: Matching Completeness and Goodness of Matches Across Propensity-Matching Models

eTable 5: Complete Patient Demographics for Propensity-Matched Using the Greedy $8 \rightarrow 4$ Model

eTable 6: Cox Proportional Analysis for Hazard of Death for Propensity-Matched Patients Using the Greedy $8 \rightarrow 4$ Model

eTable 7: OS of SBRT vs TAPs Cohorts Across Matching Models 


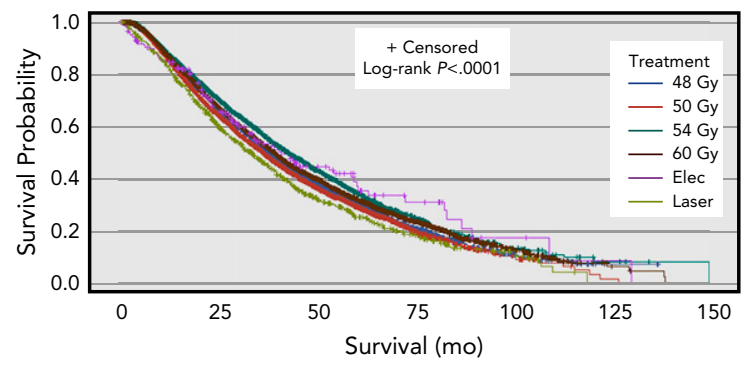

Number at risk:

$\begin{array}{rrrrrrrr}\text { 48 Gy } & 5,727 & 3,203 & 1,038 & 237 & 40 & 2 & 0 \\ 50 \text { Gy } & 9,677 & 4,845 & 1,158 & 195 & 16 & 1 & 0 \\ 54 \text { Gy } & 4,368 & 2,399 & 705 & 145 & 26 & 4 & 0 \\ 60 \text { Gy } & 6,953 & 3,983 & 1,572 & 484 & 89 & 4 & 0 \\ \text { Elec } & 172 & 95 & 36 & 13 & 3 & 1 & 0 \\ \text { Laser } & 837 & 441 & 167 & 58 & 13 & 0 & \end{array}$

eFigure 1. Kaplan-Meier curve of different stereotactic body radiation doses comprising the SBRT cohort, and different thermal ablation procedures comprising the TAPs cohort (ie, elec and laser).

Abbreviations: Elec, electrocautery; SBRT, stereotactic body radiotherapy; TAPs, thermal ablative procedures.

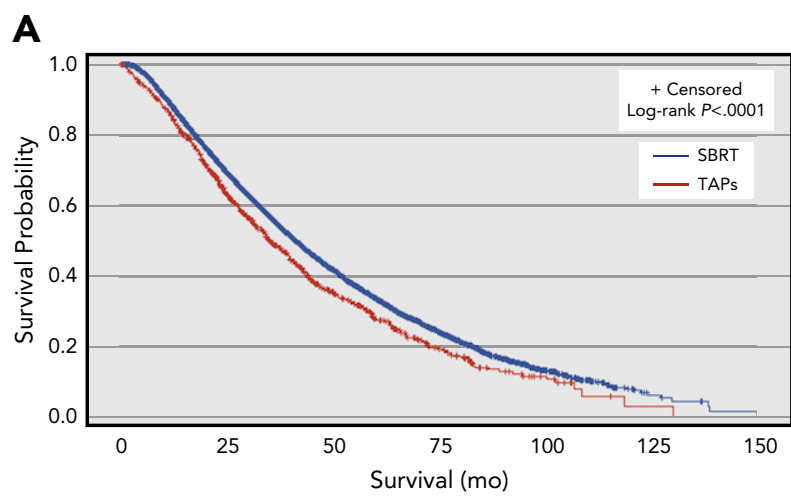

Number at risk:

$\begin{array}{rrrrrrrr}\text { SBRT } & 20,885 & 11,662 & 3,676 & 865 & 145 & 8 & 0 \\ \text { TAPs } & 870 & 480 & 177 & 55 & 12 & 1 & 0\end{array}$

B

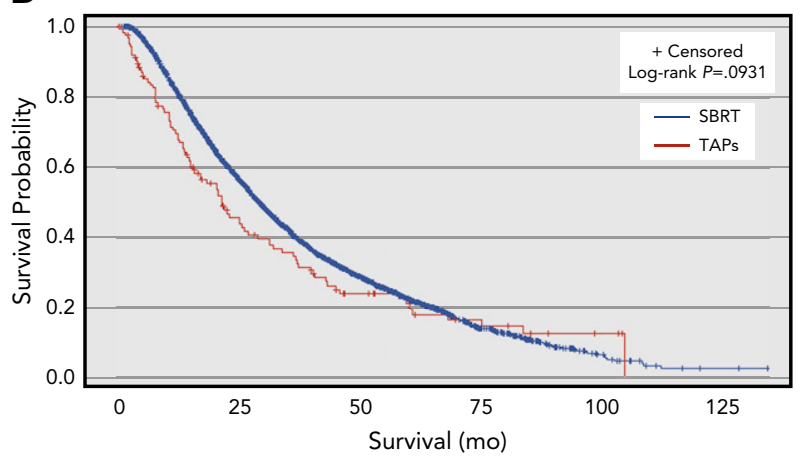

Number at risk:

$\begin{array}{rrrrrrr}\text { SBRT } & 5,577 & 2,610 & 719 & 155 & 22 & 2 \\ \text { TAPs } & 123 & 44 & 19 & 9 & 3 & 0\end{array}$

eFigure 2. Kaplan-Meier curve for (A) T1 and (B) T2 disease between SBRT and TAPs cohorts.

Abbreviations: SBRT, stereotactic body radiation therapy; TAPs, thermal ablative procedures. 


\section{2 - Baine et al}

A

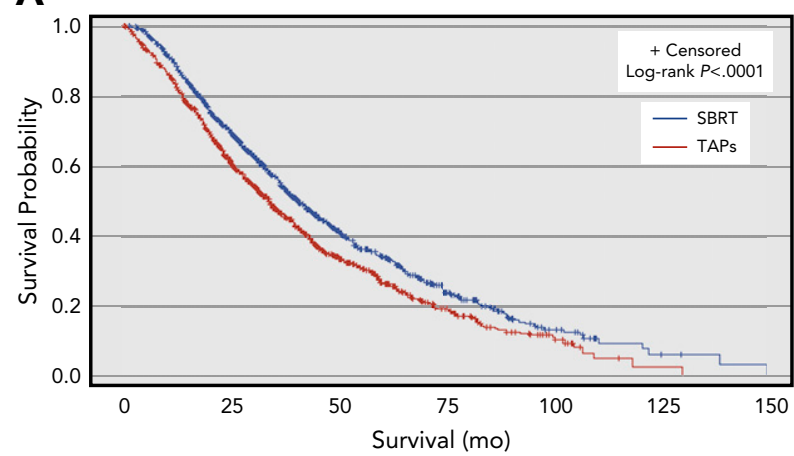

Number at risk:

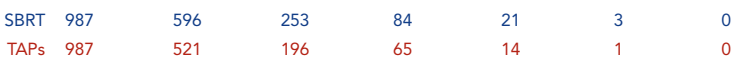

B

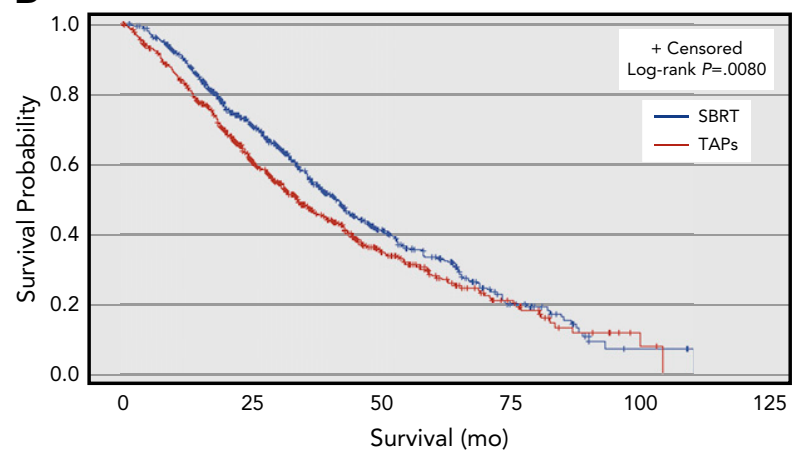

Number at risk:

\begin{tabular}{|c|c|c|c|c|c|}
\hline 620 & 414 & 202 & 86 & 22 & 3 \\
\hline 620 & 382 & 171 & 56 & 18 & 2 \\
\hline
\end{tabular}

eFigure 3. Kaplan-Meier curve of overall survival for propensity-matched patients using (A) greedy $8 \rightarrow 1$ and (B) $8 \rightarrow 5$ matching. Abbreviations: SBRT, stereotactic body radiation therapy; TAPs, thermal ablative procedures.

A

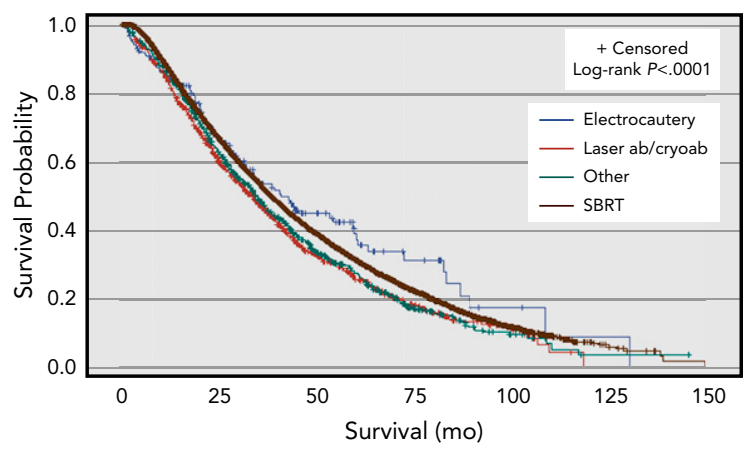

Number at risk:

$\begin{array}{rrrrrrrr}\text { Electrocautery } & 172 & 95 & 36 & 13 & 3 & 1 & 0 \\ \text { Laser ab/cryoab } & 837 & 441 & 167 & 58 & 13 & 0 & \\ \text { Other } & 740 & 432 & 176 & 51 & 12 & 1 & 0 \\ \text { SBRT } & 26,725 & 14,430 & 4,473 & 1,061 & 171 & 11 & 0\end{array}$

B

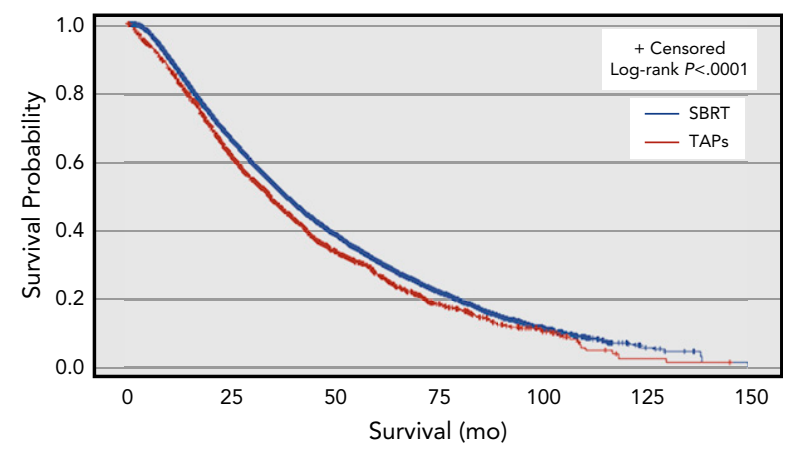

Number at risk:

$\begin{array}{rrrrrrrr}\text { SBRT } & 26,725 & 14,430 & 4,473 & 1,061 & 171 & 11 & 0 \\ \text { TAPs } & 1,749 & 968 & 379 & 122 & 28 & 2 & 0\end{array}$

eFigure 4. Kaplan-Meier curve of different thermal ablation procedures available in the NCDB, including (A) "local tumor destruction, not otherwise specified" and (B) compiling these into a new, theoretical TAPs cohort.

Abbreviations: ab, ablation; cryoab, cryoablation; NCDB, National Cancer Database; SBRT, stereotactic body radiation therapy; TAPs, thermal ablative procedures. 
Baine et al - 3

eTable 1. Dose and Fractionation Patterns of the SBRT Cohort $(\mathrm{N}=26,725)$

\begin{tabular}{|lc|}
\hline \multicolumn{1}{|c|}{$\mathbf{N}(\%)$} \\
\hline \begin{tabular}{l} 
Dose, Gy \\
\hline 48
\end{tabular} & $5,727(21.4 \%)$ \\
\hline 50 & $9,677(36.2 \%)$ \\
\hline 54 & $4,368(16.3 \%)$ \\
\hline 60 & $6,953(26.0 \%)$ \\
\hline Fractions & \\
\hline 3 & $7,835(29.3 \%)$ \\
\hline 4 & $7,212(27.0 \%)$ \\
\hline 5 & $9,291(34.8 \%)$ \\
\hline Other & $2,387(8.9 \%)$ \\
\hline
\end{tabular}

Abbreviation: SBRT, stereotactic body radiation therapy. 


\section{eTable 2. Complete List of Patient Demographics}

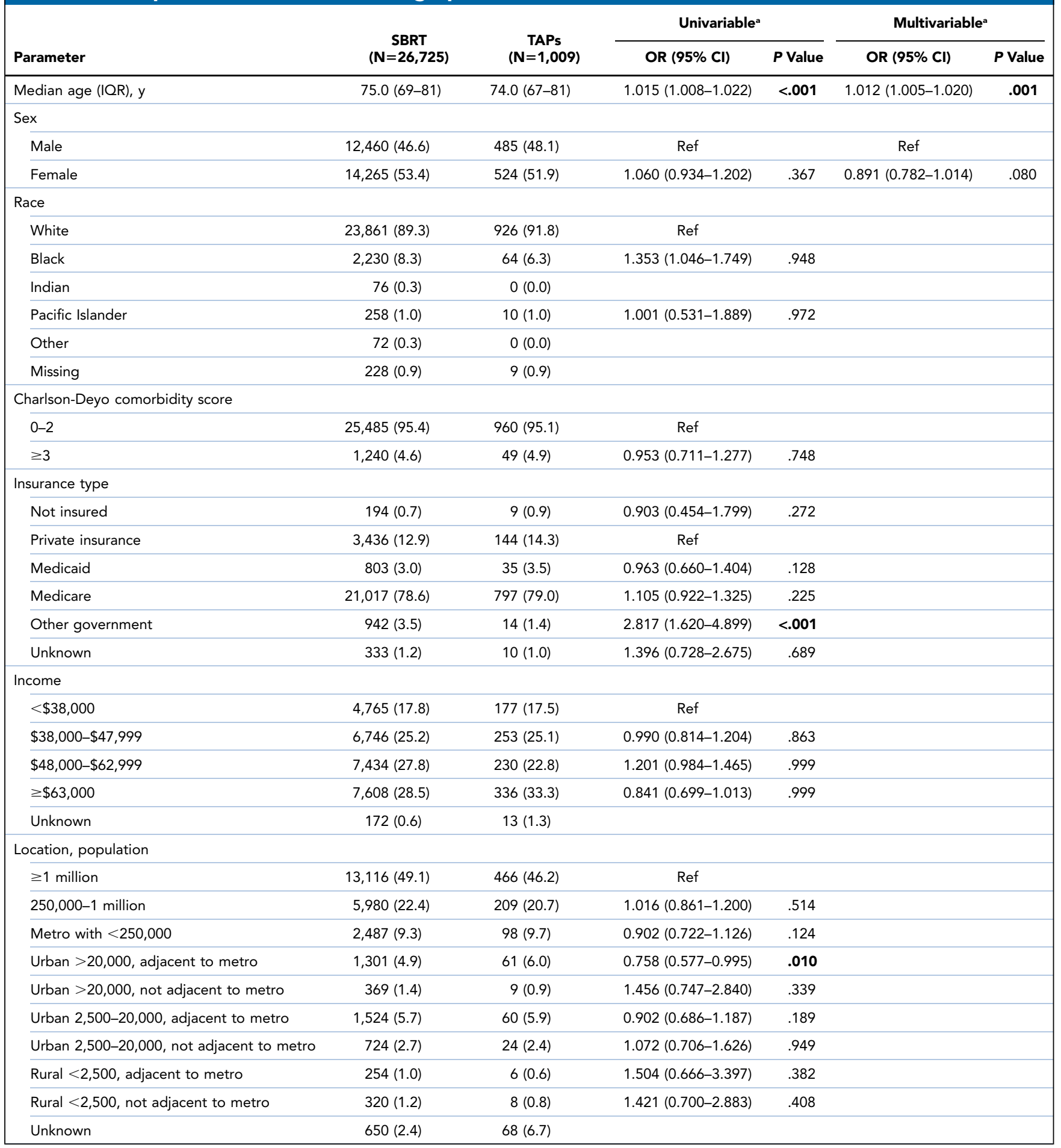

(continued on next page)

Statistically significant $P$ values are bold.

Abbreviations: IQR, interquartile range; metro, metropolitan area; NA, not available; NOS, not otherwise specified; OR, odds ratio; SBRT, stereotactic body radiation therapy; TAPs, thermal ablative procedures.

aEnd point: receipt of SBRT. 


\section{eTable 2. Complete List of Patient Demographics (cont.)}

\begin{tabular}{|c|c|c|c|c|c|c|}
\hline \multirow[b]{2}{*}{ Parameter } & \multirow{2}{*}{$\begin{array}{c}\text { SBRT } \\
(\mathrm{N}=26,725)\end{array}$} & \multirow{2}{*}{$\begin{array}{c}\text { TAPs } \\
(\mathrm{N}=1,009)\end{array}$} & \multicolumn{2}{|l|}{ Univariable $^{a}$} & \multicolumn{2}{|l|}{ Multivariable $^{a}$} \\
\hline & & & OR $(95 \% \mathrm{Cl})$ & $P$ Value & OR $(95 \% \mathrm{Cl})$ & $P$ Value \\
\hline \multicolumn{7}{|l|}{ Residents in ZIP code without high school diploma } \\
\hline $20 \%-28.9 \%$ & $7,147(26.7)$ & $257(25.5)$ & $0.928(0.748-1.151)$ & .681 & & \\
\hline $14 \%-19.9 \%$ & $9,438(35.3)$ & $377(37.4)$ & $0.836(0.682-1.024)$ & .108 & & \\
\hline Unknown & $164(0.6)$ & $12(1.2)$ & & & & \\
\hline \multicolumn{7}{|l|}{ Facility type } \\
\hline Academic institute & $11,751(44.0)$ & $496(49.2)$ & Ref & & Ref & \\
\hline Community cancer program & $822(3.1)$ & $56(5.6)$ & $0.619(0.466-0.824)$ & $<.001$ & $0.506(0.376-0.682)$ & .015 \\
\hline Comprehensive community cancer program & $10,647(39.8)$ & $327(32.4)$ & $1.374(1.192-1.584)$ & $<.001$ & $1.115(0.959-1.297)$ & .643 \\
\hline \multicolumn{7}{|l|}{ Facility location } \\
\hline New England & $1,447(5.4)$ & $159(15.8)$ & Ref & & Ref & \\
\hline Middle Atlantic & $4,110(15.4)$ & $211(20.9)$ & $2.141(1.728-2.653)$ & $<.001$ & $2.160(1.732-2.695)$ & $<.001$ \\
\hline South Atlantic & $5,934(22.2)$ & $193(19.1)$ & $3.379(2.718-4.200)$ & $<.001$ & $3.452(2.746-4.339)$ & $<.001$ \\
\hline East North Central & $5,351(20.0)$ & $177(17.5)$ & $3.322(2.661-4.147)$ & $<.001$ & $3.394(2.690-4.283)$ & $<.001$ \\
\hline East South Central & $1,670(6.2)$ & $63(6.2)$ & $2.913(2.158-3.933)$ & $<.001$ & $2.543(1.865-3.468)$ & $<.001$ \\
\hline West North Central & $3,355(12.6)$ & $45(4.5)$ & $8.193(5.851-11.472)$ & $<.001$ & $9.193(6.523-12.954)$ & $<.001$ \\
\hline West South Central & $1,512(5.7)$ & $72(7.1)$ & $2.308(1.731-3.077)$ & $<.001$ & $2.566(1.905-3.457)$ & $<.001$ \\
\hline Mountain & $996(3.7)$ & $27(2.7)$ & $4.054(2.674-6.144)$ & $<.001$ & $3.714(2.427-5.683)$ & $<.001$ \\
\hline Pacific & $2,346(8.8)$ & $53(5.3)$ & $4.866(3.542-6.686)$ & $<.001$ & $4.525(3.257-6.289)$ & $<.001$ \\
\hline Other & $1,436(5.4)$ & $112(11.1)$ & & & & \\
\hline Median year of diagnosis (IQR) & $2012(2010-2013)$ & $2010(2008-2012)$ & $1.289(1.258-1.321)$ & $<.001$ & $1.334(1.299-1.369)$ & $<.001$ \\
\hline Median tumor size (IQR), mm & $21(15-29)$ & $18(14-25)$ & $1.035(1.027-1.043)$ & $<.001$ & & \\
\hline \multicolumn{7}{|l|}{ Clinical stage } \\
\hline IA & $19,856(74.3)$ & $821(81.4)$ & Ref & & Ref & \\
\hline IB & $5,659(21.2)$ & $135(13.4)$ & $1.733(1.441-2.084)$ & $<.001$ & $1.860(1.538-2.249)$ & $<.001$ \\
\hline "I" NOS & $1,210(4.5)$ & $53(5.2)$ & $0.944(0.711-1.254)$ & .231 & $0.967(0.719-1.299)$ & .251 \\
\hline \multicolumn{7}{|l|}{ Tumor grade } \\
\hline 1 & $2,156(8.1)$ & $91(9.0)$ & Ref & & Ref & \\
\hline 2 & $4,446(16.6)$ & $183(18.1)$ & $1.025(0.793-1.325)$ & .603 & $0.872(0.663-1.145)$ & .055 \\
\hline 3 & $5,052(18.9)$ & $171(16.9)$ & $1.247(0.962-1.616)$ & .771 & $1.164(0.883-1.536)$ & .515 \\
\hline 4 & $95(0.4)$ & $6(0.7)$ & $0.668(0.285-1.566)$ & .253 & $1.311(0.536-3.210)$ & .603 \\
\hline Unknown & $14,976(56.0)$ & $558(55.3)$ & & & & \\
\hline
\end{tabular}

Statistically significant $P$ values are bold.

(continued on next page)

Abbreviations: IQR, interquartile range; metro, metropolitan area; NA, not available; NOS, not otherwise specified; OR, odds ratio; SBRT, stereotactic body radiation therapy; TAPs, thermal ablative procedures.

and point: receipt of SBRT. 


\section{eTable 2. Complete List of Patient Demographics (cont.)}

\begin{tabular}{|c|c|c|c|c|c|c|}
\hline \multirow[b]{2}{*}{ Parameter } & \multirow{2}{*}{$\begin{array}{c}\text { SBRT } \\
(N=26,725)\end{array}$} & \multirow{2}{*}{$\begin{array}{c}\text { TAPs } \\
(\mathbf{N}=1,009)\end{array}$} & \multicolumn{2}{|l|}{ Univariable $^{a}$} & \multicolumn{2}{|c|}{ Multivariable $^{a}$} \\
\hline & & & OR $(95 \% \mathrm{Cl})$ & $P$ Value & OR $(95 \% \mathrm{Cl})$ & $P$ Value \\
\hline \multicolumn{7}{|l|}{ Primary site } \\
\hline Upper lobe & $16,091(60.2)$ & 564 (55.9) & Ref & & & \\
\hline Bronchus & $94(0.4)$ & $41(4.1)$ & $0.080(0.055-0.117)$ & $<.001$ & & \\
\hline Middle lobe & $1,232(4.6)$ & $40(4.0)$ & $1.080(0.779-1.495)$ & .962 & & \\
\hline Lower lobe & $8,691(32.5)$ & 339 (33.6) & $0.899(0.784-1.031)$ & .956 & & \\
\hline Lung/Bronchus overlap & $57(0.2)$ & $0(0.0)$ & & & & \\
\hline Unknown & $560(2.1)$ & $25(2.5)$ & & & & \\
\hline \multicolumn{7}{|l|}{ Tumor laterality } \\
\hline Right & $14,872(55.6)$ & $529(52.4)$ & Ref & & & \\
\hline Left & $11,739(43.9)$ & $438(43.4)$ & $0.953(0.838-1.085)$ & .944 & & \\
\hline Unknown/NA & $114(0.4)$ & $42(4.2)$ & & & & \\
\hline \multicolumn{7}{|l|}{ Mortality } \\
\hline $30-d$ & $3(0.01 \%)$ & $7(0.7 \%)$ & & & & \\
\hline $90-d$ & $134(0.5 \%)$ & $38(3.8 \%)$ & & & & \\
\hline 6-mo & $971(3.6 \%)$ & $76(7.5 \%)$ & & & & \\
\hline Median days after diagnosis until treatment (IQR) & $56(37-84)$ & $44(22-76)$ & & & & \\
\hline
\end{tabular}

Statistically significant $P$ values are bold.

Abbreviations: IQR, interquartile range; metro, metropolitan area; NA, not available; NOS, not otherwise specified; OR, odds ratio; SBRT, stereotactic body radiation therapy; TAPs, thermal ablative procedures.

and point: receipt of SBRT. 


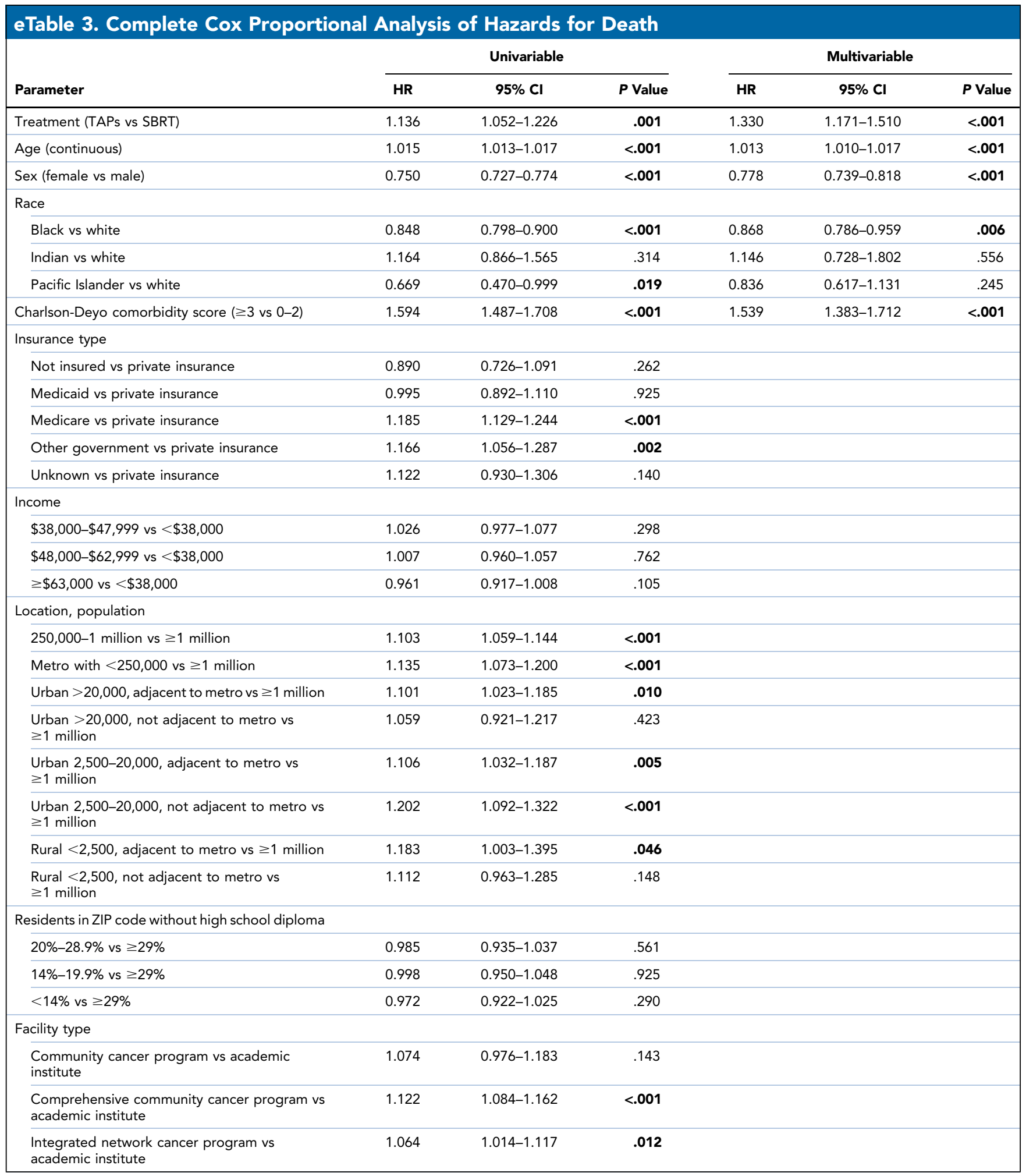

Statistically significant $P$ values are bold.

(continued on next page)

Abbreviations: HR; hazard ratio; metro, metropolitan area; SBRT, stereotactic body radiation therapy; TAPs, thermal ablative procedures. 


\begin{tabular}{|c|c|c|c|c|c|c|}
\hline Parameter & HR & $95 \% \mathrm{Cl}$ & $P$ Value & HR & $95 \% \mathrm{Cl}$ & $P$ Value \\
\hline \multicolumn{7}{|l|}{ Facility location } \\
\hline Middle Atlantic vs New England & 0.928 & $0.860-1.005$ & .056 & 0.949 & $0.826-1.091$ & .464 \\
\hline South Atlantic vs New England & 0.964 & $0.897-1.037$ & .329 & 0.965 & $0.845-1.103$ & .606 \\
\hline East South Central vs New England & 1.090 & $0.996-1.193$ & .062 & 0.998 & $0.851-1.170$ & .977 \\
\hline West North Central vs New England & 1.016 & $0.939-1.098$ & .693 & 1.005 & $0.879-1.150$ & .939 \\
\hline West South Central vs New England & 0.863 & $0.786-0.947$ & .002 & 0.883 & $0.757-1.030$ & .114 \\
\hline Mountain vs New England & 0.971 & $0.875-1.078$ & .584 & 0.944 & $0.795-1.120$ & .507 \\
\hline Adenocarcinoma vs squamous & 0.726 & $0.700-0.753$ & $<.001$ & 0.828 & $0.782-0.877$ & $<.001$ \\
\hline Non-small cell vs squamous & 0.859 & $0.821-0.899$ & $<.001$ & 0.903 & $0.823-0.991$ & .031 \\
\hline \multicolumn{7}{|l|}{ Tumor grade } \\
\hline 2 vs 1 & 1.415 & $1.317-1.520$ & $<.001$ & 1.291 & $1.188-1.403$ & $<.001$ \\
\hline 3 vs 1 & 1.475 & $1.375-1.582$ & $<.001$ & 1.309 & $1.203-1.425$ & $<.001$ \\
\hline 4 vs 1 & 1.308 & $1.010-1.693$ & .042 & 1.151 & $0.782-1.694$ & .477 \\
\hline Tumor size (continuous) & 1.003 & $1.003-1.003$ & $<.001$ & & & \\
\hline Clinical stage (IB vs IA) & 1.462 & $1.410-1.517$ & $<.001$ & 1.440 & $1.361-1.524$ & $<.001$ \\
\hline \multicolumn{7}{|l|}{ Primary site } \\
\hline
\end{tabular}

Statistically significant $P$ values are bold.

Abbreviations: HR; hazard ratio; metro, metropolitan area; SBRT, stereotactic body radiation therapy; TAPs, thermal ablative procedures. 


\section{eTable 4. Matching Completeness and Goodness of Matches Across Propensity-Matching Models}

\begin{tabular}{|c|c|c|c|c|c|}
\hline \multirow[b]{2}{*}{ Algorithm } & \multirow{2}{*}{$\begin{array}{c}\text { Matching Completeness } \\
\text { TAPs Cases } \\
\text { n (\% matched })\end{array}$} & \multicolumn{2}{|c|}{$\begin{array}{c}\text { Example of Corrected Patient Characteristics } \\
\text { After Matching }\end{array}$} & \multicolumn{2}{|c|}{ Goodness of Matches } \\
\hline & & $\begin{array}{l}\text { Age of TAPs Patients, } y \\
\text { Median (mean) }\end{array}$ & $\begin{array}{l}\text { Age of SBRT Patients, y } \\
\text { Median (mean) }\end{array}$ & $\begin{array}{l}\text { Average Difference in } \\
\text { Propensity Scores }\end{array}$ & $\begin{array}{l}\text { Absolute Difference in } \\
\text { Propensity Scores }\end{array}$ \\
\hline Unmatched & 1,009 & $74.0(73.3)$ & $75.0(74.4)$ & & \\
\hline 8-digit & 80 (7.9\%) & $76.0(75.6)$ & $76.0(75.5)$ & 1.6E-11 & 1.3E-9 \\
\hline $8 \rightarrow 7$ & 97 (9.6\%) & $76.0(75.6)$ & $75.0(74.7)$ & $6.3 \mathrm{E}-9$ & $6.1 \mathrm{E}-7$ \\
\hline $8 \rightarrow 6$ & $222(22.0 \%)$ & $76.0(74.8)$ & $75.0(74.7)$ & $2.2 \mathrm{E}-7$ & $5.0 \mathrm{E}-5$ \\
\hline $8 \rightarrow 5$ & $620(61.4 \%)$ & $75.0(74.0)$ & $75.0(74.6)$ & $2.6 \mathrm{E}-6$ & $1.6 \mathrm{E}-3$ \\
\hline $8 \rightarrow 4$ & $853(84.5 \%)$ & $75.0(73.8)$ & $75.0(74.4)$ & $1.2 \mathrm{E}-5$ & $1.0 \mathrm{E}-2$ \\
\hline $8 \rightarrow 3$ & 956 (94.7\%) & $75.0(73.7)$ & $75.0(74.2)$ & $5.2 \mathrm{E}-5$ & $5.0 \mathrm{E}-2$ \\
\hline $8 \rightarrow 1$ & 987 (97.8\%) & 75.0 (73.7) & 75.0 (74.1) & $1.6 \mathrm{E}-4$ & $1.6 \mathrm{E}-1$ \\
\hline
\end{tabular}

Bolded values are statistically significant.

Abbreviations: SBRT, stereotactic body radiation therapy; TAPs, thermal ablative procedures. 
eTable 5. Complete Patient Demographics for Propensity-Matched Patients Using the Greedy $8 \rightarrow 4$ Model

\begin{tabular}{|c|c|c|c|}
\hline Parameter & $\begin{array}{c}\text { SBRT (N=853) } \\
n(\%)\end{array}$ & $\begin{array}{c}\text { TAPs }(\mathbf{N}=853) \\
n(\%)\end{array}$ & $\frac{\text { Univariable }^{\mathrm{a}}}{P \text { Value }}$ \\
\hline Median age (IQR), y & $75.0(69-80)$ & $74.0(68-81)$ & \\
\hline \multicolumn{4}{|l|}{ Sex } \\
\hline Male & $405(47.5)$ & $411(48.2)$ & \\
\hline Female & $448(52.5)$ & $442(51.8)$ & \\
\hline \multicolumn{4}{|l|}{ Race } \\
\hline White & $754(88.4)$ & $786(92.1)$ & \\
\hline Black & $78(9.1)$ & $52(6.1)$ & \\
\hline Indian & $2(0.2)$ & $0(0.0)$ & \\
\hline Pacific Islander & $6(0.7)$ & $9(1.1)$ & \\
\hline Other & $5(0.6)$ & $0(0.0)$ & \\
\hline Missing & $8(0.9)$ & $6(0.7)$ & \\
\hline \multicolumn{4}{|l|}{ Charlson-Deyo comorbidity score } \\
\hline 0 & $451(52.9)$ & $436(51.1)$ & \\
\hline 1 & $267(31.3)$ & $264(31.0)$ & \\
\hline 2 & $100(11.7)$ & $112(13.1)$ & \\
\hline$\geq 3$ & $35(4.1)$ & $41(4.8)$ & \\
\hline \multicolumn{4}{|l|}{ Insurance type } \\
\hline Not insured & $7(0.8)$ & $7(0.8)$ & Ref \\
\hline Private insurance & $98(11.5)$ & $111(13)$ & \\
\hline Medicaid & $28(3.3)$ & $32(3.8)$ & \\
\hline Medicare & $683(80.1)$ & $681(79.8)$ & \\
\hline Other government & $29(3.4)$ & $13(1.5)$ & .017 \\
\hline Unknown & $8(0.9)$ & $9(1.1)$ & \\
\hline \multicolumn{4}{|l|}{ Income } \\
\hline$<\$ 38,000$ & $158(18.5)$ & $156(18.3)$ & \\
\hline$\$ 38,000-\$ 47,999$ & $210(24.6)$ & $223(26.1)$ & \\
\hline$\$ 48,000-\$ 62,999$ & $227(26.6)$ & $192(22.5)$ & \\
\hline$\geq \$ 63,000$ & $255(29.9)$ & $270(31.7)$ & \\
\hline Unknown & $3(0.4)$ & $12(1.4)$ & \\
\hline \multicolumn{4}{|l|}{ Location, population } \\
\hline$\geq 1$ million & $422(49.5)$ & $384(45.0)$ & \\
\hline $250,000-1$ million & $210(24.6)$ & $189(22.2)$ & \\
\hline Metro with $<250,000$ & $67(7.9)$ & $86(10.1)$ & \\
\hline Urban $>20,000$, adjacent to metro & $46(5.4)$ & $52(6.1)$ & \\
\hline Urban $>20,000$, not adjacent to metro & $7(0.8)$ & $7(0.8)$ & \\
\hline Urban $2,500-20,000$, adjacent to metro & $45(5.3)$ & $54(6.3)$ & \\
\hline Urban $2,500-20,000$, not adjacent to metro & $29(3.4)$ & $23(2.7)$ & \\
\hline Rural $<2,5000$, adjacent to metro & $1(0.1)$ & $6(0.7)$ & \\
\hline Rural $<2,5000$, not adjacent to metro & $8(0.9)$ & $8(0.9)$ & \\
\hline Unknown & $18(2.1)$ & $44(5.2)$ & \\
\hline
\end{tabular}




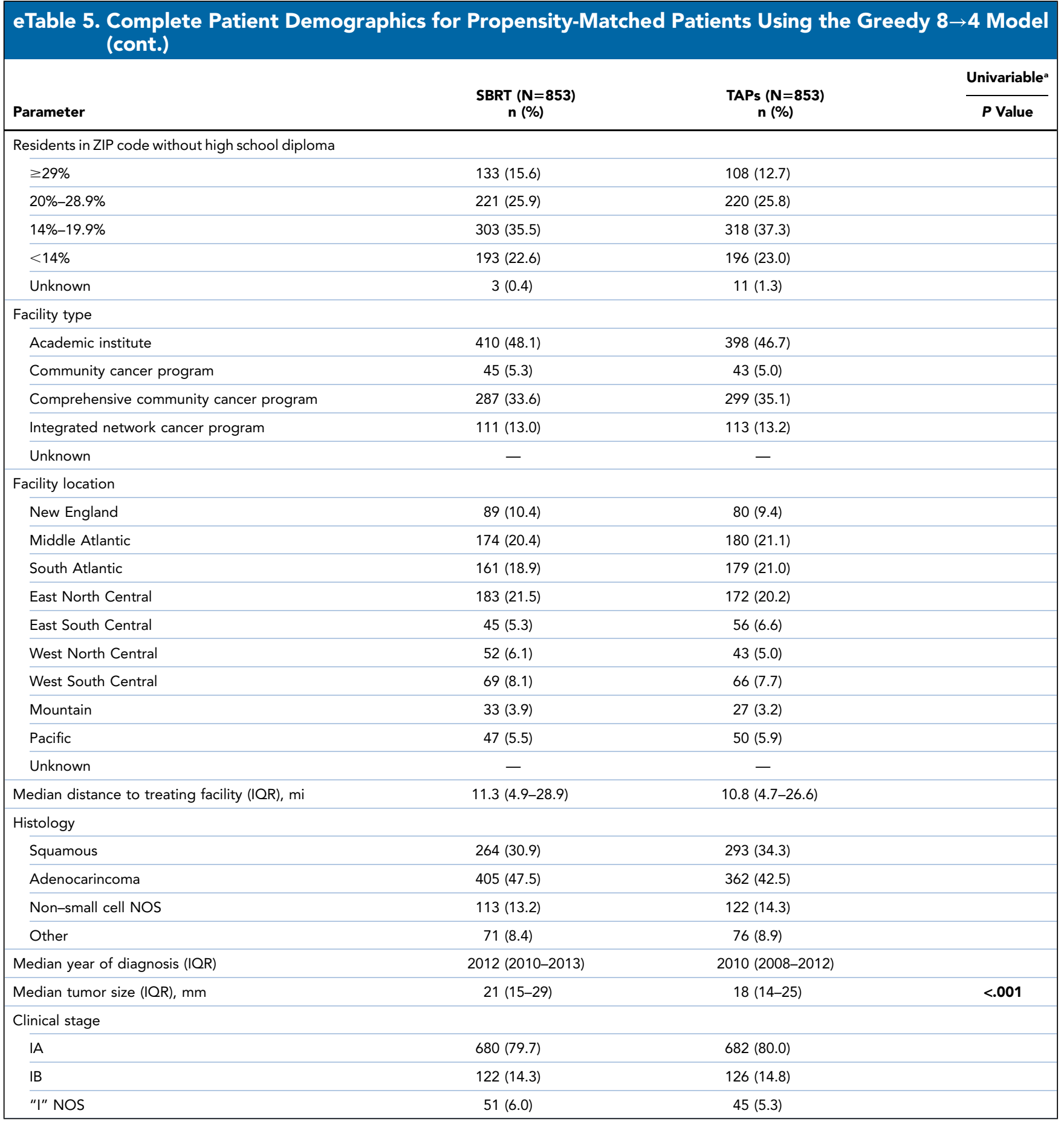

Statistically significant $P$ values are bold.

(continued on next page)

Abbreviations: IQR, interquartile range; metro, metropolitan area; NA, not available; NOS, not otherwise specified; SBRT, stereotactic body radiation therapy; TAPs, thermal ablative procedures.

aEnd point: receipt of SBRT. 


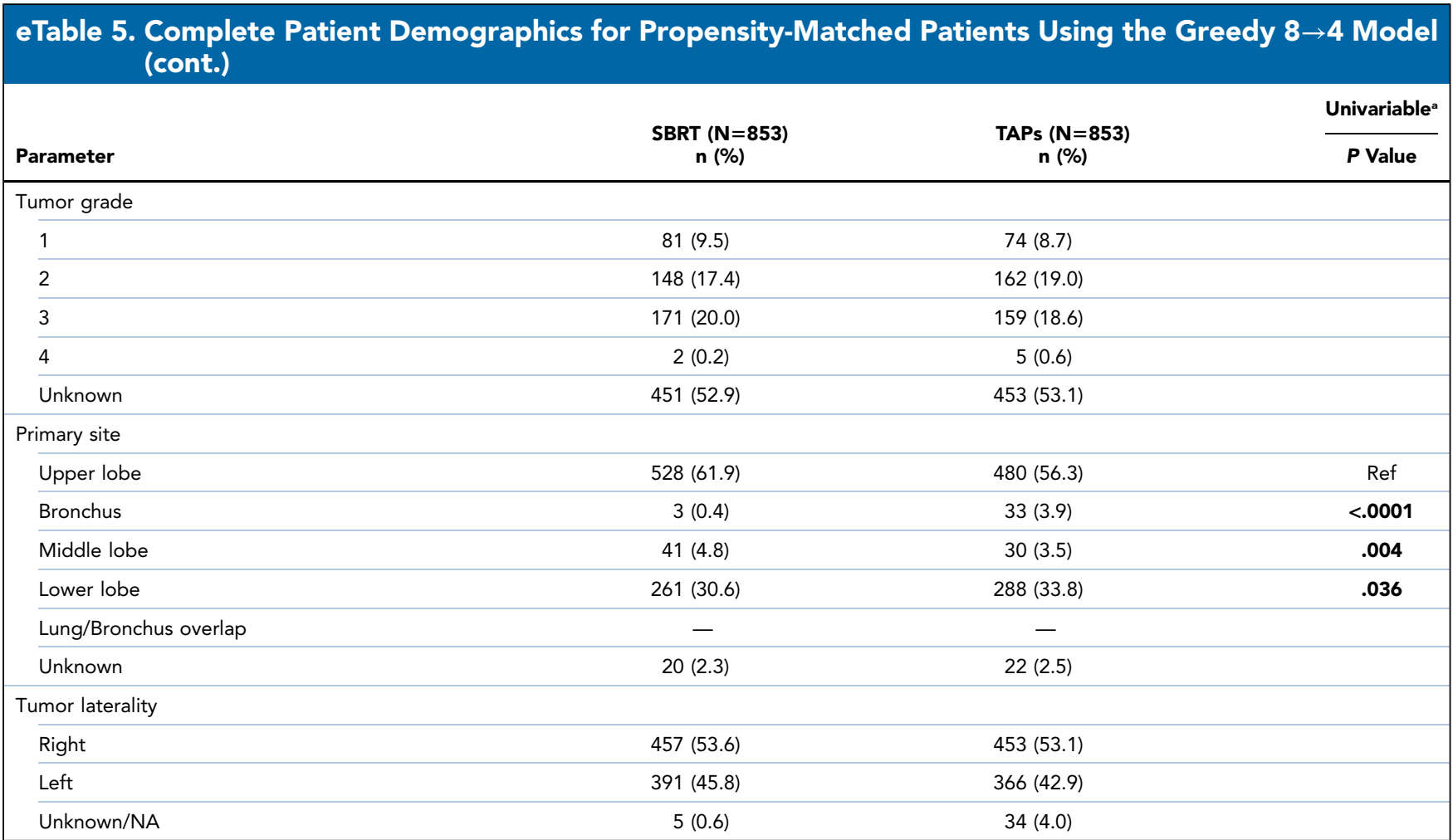

Statistically significant $P$ values are bold.

Abbreviations: IQR, interquartile range; metro, metropolitan area; NA, not available; NOS, not otherwise specified; SBRT, stereotactic body radiation therapy; TAPs, thermal ablative procedures.

aEnd point: receipt of SBRT. 


\begin{tabular}{|c|c|c|c|c|c|c|}
\hline Parameter & \multicolumn{3}{|c|}{ Univariable } & \multicolumn{3}{|c|}{ Multivariable } \\
\hline Treatment (TAPs vs SBRT) & 1.270 & $1.085-1.486$ & .003 & 1.265 & $1.062-1.506$ & .008 \\
\hline Age (continuous) & 1.021 & $1.007-1.035$ & .003 & 1.024 & $1.009-1.040$ & .002 \\
\hline Charlson-Deyo comorbidity score (3 vs 0 ) & 2.612 & $1.486-4.592$ & $<.001$ & 3.067 & $1.655-5.684$ & $<.001$ \\
\hline \multicolumn{7}{|l|}{ Facility location } \\
\hline Middle Atlantic vs New England & 0.534 & $0.325-0.877$ & .013 & & & \\
\hline South Atlantic vs New England & 0.592 & $0.359-0.976$ & .040 & & & \\
\hline Pacific vs New England & 0.370 & $0.187-0.733$ & .004 & & & \\
\hline \multicolumn{7}{|l|}{ Tumor grade } \\
\hline 2 vs 1 & 3.295 & $1.903-5.703$ & $<.001$ & & & \\
\hline 3 vs 1 & 2.362 & $1.389-4.016$ & .002 & & & \\
\hline Tumor size (continuous) & 1.028 & $1.015-1.041$ & $<.001$ & & & \\
\hline Clinical stage (IB vs IA) & 2.421 & $1.705-3.440$ & $<.001$ & 2.218 & $1.518-3.241$ & $<.001$ \\
\hline
\end{tabular}

Statistically significant $P$ values are bold.

Abbreviations: HR, hazard ratio; NOS, not otherwise specified; SBRT, stereotactic body radiation therapy; TAPs, thermal ablative procedures.

\section{eTable 7. OS of SBRT vs TAPs Cohorts Across Matching Models}

\begin{tabular}{|c|c|c|c|c|c|c|c|c|}
\hline Model & \multicolumn{2}{|c|}{ mOS (mo) } & \multicolumn{2}{|c|}{$1-y$ OS (\%) } & \multicolumn{2}{|c|}{ 2-y OS (\%) } & \multicolumn{2}{|c|}{ 5-y OS (\%) } \\
\hline Unmatched & 37.7 & 33.5 & 86.7 & 83.1 & 67.5 & 62.7 & 30.6 & 26.9 \\
\hline $8 \rightarrow 1$ & 39.8 & 33.4 & 88.5 & 82.8 & 69.3 & 62.4 & 33.7 & 26.1 \\
\hline $8 \rightarrow 4$ & 40.4 & 33.4 & 89.0 & 82.9 & 69.7 & 62.7 & 34.4 & 26.4 \\
\hline $8 \rightarrow 5$ & 40.4 & 34.2 & 88.1 & 82.0 & 69.1 & 63.1 & 33.7 & 29.2 \\
\hline
\end{tabular}

Abbreviations: mOS, median overall survival; OS, overall survival; SBRT, stereotactic body radiation therapy; TAPs, thermal ablative procedures. 